\title{
Reflections on Dr. Donald A.B. Lindberg and Native Voices
}

\author{
Katherine GOTTLIEB M.B.A., D.P.S. ${ }^{\mathrm{a}, 1}$, Cynthia LINDQUIST Ph.D. ${ }^{\mathrm{b}}$, \\ Theodore A. MALA M.D., M.P.H. ${ }^{c}$, Marjorie K. Leimomi M. MAU M.D. M.S. ${ }^{d}$ \\ ${ }^{a}$ Katherine Gottlieb Strategies, Anchorage, AK, U.S. \\ ${ }^{\mathrm{b}}$ Cankdeska Cikana Community College, Spirit Lake Dakota Tribe, U.S. \\ c Southcentral Foundation (retired), Anchorage, AK, U.S. \\ d John A. Burns School of Medicine, University of Hawai'i at Manoa, HI, U.S.
}

\begin{abstract}
Personal reflections on Donald A.B. Lindberg M.D. are offered by four Native American leaders who were instrumental in the successful development of the National Library of Medicine's (NLM) Native Voices Exhibition: Stories of Health and Wellness from American Indians, Alaska Natives and Native Hawaiians. A uniquely collaborative effort, the exhibition features nearly 100 videographed interviews conducted by Dr. Lindberg with Native elders, healers, leaders, and people. He is credited with the incorporation of indigenous peoples' healing knowledge in a personal and relational way, making for a wonderful journey together that was a very large chapter in his life and that of the authors.
\end{abstract}

Keywords. U.S. National Library of Medicine, Donald A.B. Lindberg M.D., American Indian, Alaska Native, Native Hawaiian, Indigenous People, Native Healing, Native Voices Exhibition

\section{Introduction}

A companion chapter in this book, Native Voices Exhibition: Stories of Health, Wellness, and Illness from American Indians, Alaska Natives and Native Hawaiians details the origin, development, implementation, and celebration of a most unusual exhibition undertaken under the leadership of Donald A.B. Lindberg M.D., Director of the U.S. National Library of Medicine (NLM) [1]. Native Voices was a highly visible and frequently visited presence from 2011-2015 at the NLM, located on the campus of the National Institutes of Health (NIH) in Bethesda, MD. Traveling versions subsequently visited locations throughout the U.S. from 2013 to early 2020. An online version continues to be accessible on the Native Voices website where videographed interviews and other exhibition resources can be found [2].

The Native Voices exhibition was a technical and human achievement that told a remarkable story, largely unknown to many, of Native health and wellness. At its core, it is told in the Native voice as personal videographed interviews conducted by Dr. Lindberg with more than 80 elders, healers, and community leaders. They are representative indigenous peoples - American Indians, Alaska Natives and Native Hawaiians, who live in diverse tribal lands, reservations, villages, and urban communities.

\footnotetext{
${ }^{1}$ Corresponding author: Katherine Gottlieb, E-mail: katherinegottlieb@gmail.com
} 
Scores of artifacts enhanced the exhibition, and two symbolic icons delivering powerful messages of Native healing were commissioned. A scale model of the Hokule'a, the Native Hawaiian voyaging canoe occupied a place of honor in the NLM lobby and has since been repatriated to Hawaii; the Healing Totem crafted by an indigenous carver in Washington State sits permanently near the NLM entrance.

Dr. Lindberg, along with his NLM outreach team, earned our trust through multiple visitations organized as Listening Circles, Tribal Consultations, and as purposeful individual trips of special interest to, for example, remote Indian reservations in North Dakota and elsewhere; two comprehensive health centers designed for indigenous peoples in Anchorage and Oahu offering both western and traditional medicine; an Alaskan Innuit village in the Arctic Circle, and a Hansen's disease enclave on Kalaupapa, Hawaii. The latter two destinations are accessible only by small plane. In the end, it was Dr. Lindberg's sincerity of purpose to tell our story accurately, respectfully, and empathetically that encouraged us to work with him and to facilitate access and cooperation by others.

\section{Our Personal Reflections}

As this book project took form, Elliot R. Siegel Ph.D., the editor of the Outreach Section approached us with a request to contribute a chapter that would complement the Native Voices exhibition chapter. (Dr. Siegel was a lead member of Dr. Lindberg's outreach team). Our chapter would serve as a personal recounting from the Native perspective of the exhibition's origins and development, and offer reflections on our experiences with Dr. Lindberg that helped make the Native Voices exhibition possible:

With Dr. Donald Lindberg's passing in 2019, several of his close colleagues are developing a tribute book to Don's memory and accomplishments. Mary Lindberg is an enthusiastic supporter. We envision this chapter to be an opportunity for each of you to come together and tell your stories about your experiences working with Don Lindberg and the NLM outreach team; educating us, opening doors, and helping ensure that the spirit and culture of Native Medicine was accurately portrayed in the environs of NLM and the National Institutes of Health (NIH), a bastion of Western medicine. As editor of the Outreach Section, I leave it to you to shape the chapter as you see fit - it is Don's story as told from your perspective. We know how meaningful this work was to Don, he gave so much of his time, and he learned so much from your teachings.

\section{Cynthia Lindquist, Ph.D., President, Cankdeska Cikana Community College, Ta'sunka Wicahpi Winyan (Star Horse Woman) Spirt Lake Dakota Tribe}

In remembering Dr. Lindberg, I see a tall, grandfatherly, and unassuming man. Little did I know the breadth of his intelligence, kindness, and insight...or the magnitude of NIH/NLM under Don's leadership. America's medical library was led by this thoughtful leader and he cared about people of color and underserved communities.

During the 1990s I worked for the Indian Health Service and helped to establish the National Indian Women's Health Resource Center, located in Tahlequah, OK. The Executive Director, Pam Iron, and I were approached by Ted Mala M.D. and Dr. Lindberg to organize and coordinate a series of Listening Circles for NLM. Pam, Ted, 
and I had come up through the ranks as tribal members involved in tribal health and we understood the need for officials (government, public, or private) to be engaged at the community level - to really 'listen' to the people prior to setting up programs or services. Dr. Lindberg heard Dr. Mala's insight and readily agreed... thus three Listening Sessions were held in indigenous country - the Great Plains, Hawaii, and Alaska. Our intent was to demonstrate the diversity of indigenous peoples and communities.

Dr. Lindberg and his team of professionals were engaged and they did 'listen'! Each Session was organized by a group of local health workers and elders but also with elected tribal officials. The goal was to hear from the indigenous people (the public) directly but also to share general information about NLM as most Natives had never heard of NLM or were aware of what it does. I believe Dr. Lindberg learned that there is commonality in Native communities (history of colonization, policies to force assimilation) but there are also significant differences, particularly with cultural practices, let alone languages. This knowledge led to better engagement within the NLM system for their outreach and services to minority communities.

While Natives tend to be very suspicious of the "Great White Father" mentality of the federal government - and that sentiment lingered with the Listening Sessions - Dr. Lindberg's follow up (i.e., sending computers and books to the very rural, isolated community libraries visited) was efficient and timely. I believe that the Listening Sessions were the foundation for the Native Voices exhibition.

Dr. Lindberg also took to heart my concern that he had not heard enough from traditional healers (medicine men) and thus arranged for a series of interviews during the annual tribal college student conference in Bismarck, ND in 2011. Seven healers from the Northern Plains, including one from Canada, were interviewed by Dr. Lindberg about healing arts, sustainable development, behavioral health, death, and other topics.

These interviews, along with the others, are now history as part of the Native Voices exhibition. Indigenous communities have suffered significant losses due to the current coronavirus pandemic and the Native Voices exhibition, information, and materials will be a resource of knowledge for our recovery.

Cankdeska Cikana Community College (CCCC) hosted the initial opening of the Native Voices traveling exhibition in 2013. While Dr. Lindberg and his wife Mary were visiting - for the second or third time - we showed them the Don Lindberg Resource Room in the Valerie Merrick Memorial Library that is operated by CCCC. NLM provided CCCC with funding throughout the years to provide internet access for our community. Don was quiet and appreciative, demonstrating his humility that is a core Dakota value. We wanted him to know that his support and monetary contribution made a difference and impacted Native lives.

My opinion of Dr. Lindberg is that of a person who takes the time to listen, to learn, and then to use his position of authority to make things happen. He did good work in a responsible manner and tried his best to affect change where he could. Dr. Lindberg is remembered in a good way as a good relative. His legacy will be noted by our grandchildren and great grandchildren - this is a high Dakota honor.

I am blessed and a better person to have known and worked for Dr. Don Lindberg. 


\section{Theodore A. Mala M.D., M.P.H., Director of Traditional Healing and Tribal Relations, Southcentral Foundation (retired)}

There are few and far between occasions when one stumbles upon greatness in the form of kind and gentle and learned men in various walks of life. Such was my experience in the 1980's meeting Dr. Donald Lindberg, the newly minted library director of the National Library of Medicine at the U.S. National Institutes of Health in Bethesda, MD.

At that time I was an Associate Professor at the University of Alaska in Anchorage. I was working with Alaska's early Arctic health scholars such as Dr. Earl Albrecht, Dr. Fred Milan and Dr. Robert Fortuine to name but a few. As I made inquiries into the newly created internet called Bitnet, I quickly learned that there was no database of U.S. Arctic Health other than some early anthropological works documenting herbal and traditional Alaska Native remedies. The national research gold standard was the Index Medicus based out of the National Library of Medicine.

The only international publication available was the Journal of Arctic Medical Research based in Helsinki and Oulu, Finland. This journal was primarily Scandinavian and documented work done in Sweden, Denmark, Iceland, Norway, and Finland. The only other works were the proceedings of the Arctic Council and the early meetings of Circumpolar Health.

This body of work not only included Scandinavia but also the United States, the Soviet Union, and Canada. Working with the Alaska Health Sciences library based in Fairbanks and eventually Anchorage, it was obvious that the focus of U.S. public health was centered in the more populous regions such as the equator. The Arctic was ignored for the most part.

Out of frustration, I turned to Alaska's legendary Senator Ted Stevens for help. He was the only one I really knew in Washington, DC. Sen. Stevens asked me to come back to his office the next day. There he brought in Margaret Heckler, the Secretary of Health and Human Services who set up a meeting for me with the new NLM Director, Don Lindberg. Thinking I was only going to meet with him, I was surprised when I arrived at the Director's Board Room to meet not only Dr. Lindberg but also Ms. Betsy Humphreys and a room filled with senior staff.

I stated our case that I felt the Arctic and circumpolar peoples were underrepresented and requested we be included in the Index Medicus database.

Dr. Lindberg agreed we should be included. Then, I will never forget his words to me. "Are there enough publications to represent the Arctic" he asked. I mentioned the Journal of the Arctic Council for starters. Then Dr, Lindberg said: "go make a tree." I replied I would advise our Arctic Health Sciences Librarian Stan Truelson who took up the challenge and ran with it.

Some years later, NLM decided to explore discussions with Native American tribes. They invited Dr. Terry Maresca to join those early discussions in Seattle. She was so involved clinically as a Native physician that she asked me to take her place which I did. Thus, my relationship with Dr. Fred Wood and his boss, Dr. Elliot Siegel was born.

Under the banner of Tribal meetings, Dr. Lindberg empowered his staff to explore the heretofore never documented arena of Traditional Medicine. Some years later at the Native Health corporation under the leadership of Dr. Katherine Gottlieb, Traditional Healing was formally recognized in clinical medicine as an equal contributor to Native Healing complimenting clinical allopathic medicine at the Alaska Native Medical Center. I spent sixteen years as its director. 
In the ' 80 's we founded the International Union of Circumpolar Health in Umea, Sweden. Dr. Jens Peter Hart Hanson was our first President. I was its first Secretary General. The Journal of Arctic Medical Research was our voice.

As Dr. Lindberg observed the healing effects of Traditional Medicine, he decided to take it a step further and document and record it for its significant contributions to American Health. We rekindled our friendship and spent much time together in his office and home thrashing out what would result in the NLM's opus magnus called "Native Voices."

Being a scholar, Dr. Lindberg wanted to hear and see first-hand the role of Traditional Healing in Indian Country. He brought a film crew with him and documented actual Native healers in their own words. This had never EVER been done before. The result was the first attempt to document a system of healing that sustained the first people's health long before western medicine arrived. Dr. Lindberg, in his deep wisdom, did not want to engage researchers to provide a secondhand account of what they observed but rather "let the traditional healers speak in their own words."

This is so significant for Indian Country. We have never been asked to speak in our own words. Usually, Indian Country accounts are in the second or third person. Dr. Lindberg invited tribal leaders and healers to the table to document their words. Native people felt honored to be included. As Dr. Gottlieb once commented, it might not be perfect or the end all resource. However, the idea is to encourage others to stand up and lend their voices to history.

Dr. Lindberg left this incredible historical resource for future generations to learn from. He not only included Alaska but also tribal nations across our country even including Hawaii vis a vis Dr. Marjorie Mau, a clinical scholar and Native Hawaiian.

I am humbled to be included in this writing. Similar to most living historical works, it is but a snapshot in the timeline of Native healing. It is well and alive and continually evolves as times change. It is not to say that one lifestyle is of more value than the other. Rather there are many roads to healing, one complimenting the other. We take what we have learned from our elders passed on from thousands of years of teachings.

Thank you Dr. Don Lindberg for letting us have a voice. You planted the seeds of wisdom for our world to learn from and evolve and grow. You and your legacy in medicine will never be forgotten. And for that we will be eternally grateful.

\section{Marjorie K. Leimomi M. Mau M.D., M.S. Professor, Department of Native Hawaiian Health, John A. Burns School of Medicine, University of Hawaii at Manoa, HI}

It was important, I believe, for Don Lindberg and the NLM team to gain a deeper understanding of who Native Hawaiians are as a people with a cultural heritage that goes back about 7,000 years ago and can trace its origins to the region of Oceania. This cultural inheritance is distinctly different than other indigenous populations in the U.S. and yet the story of how Native Hawaiians struggled to hold on to their cultural heritage, language and ancestry is similar to many other indigenous populations who were colonized, minimized, and nearly extinguished by dominant power-hungry countries from Europe and the Americas.

Traditional Native Hawaiian health practices such as medicinal plants, lomilomi (massage) and ho'oponopono (conflict resolution) are still used today alongside the practice of allopathic medicine approaches. Practitioners of traditional medicine for 
Native Hawaiians normally meant that the individual was someone who understood how to gather, prepare, and use various plants for healing - from their geographic location. That is, place-based knowledge was an important element of the practitioners' knowledge set. Another foundational element of traditional healing came from whether the "patient" was "open" to and believed in the traditional healing practice. This "readiness" to be healed was an important part of the healing process.

The willingness of our Native Hawaiian leaders and healers stemmed from preexisting trust and relationships of many of the people interviewed. But it also was dependent on Don's willingness to personally take the time to interview the individuals himself. This clearly showed the level of commitment to getting the project done right and to get it "first-hand" by Dr. Lindberg.

The commitment of resources and actually "showing up" in person as the Director of NLM spoke volumes of the Native Voices project being given the highest priority.

In Hawai'i, we had one incident when one of our younger Native Hawaiian faculty became distraught about what he thought was a racist approach to the interview being led by Dr. Lindberg. This was an unexpected response to come from an intelligent Native Hawaiian person. However, in retrospect, it demonstrated an important generational difference of how the interview questions were posed - and how it can ... for some... make a huge difference. While it was not an error on anyone's part, it highlights how some from a more recent generation interpret the use of words and how they may draw their own conclusions ... showing their own bias ... unconscious bias from a younger Native Hawaiian person.

Our Department of Native Hawaiian Health faculty, some of whom also were cultural practitioners, had a longstanding history of visiting Kalaupapa and were aware of its unique medical history and its lessons for today's health care providers. So, providing access to Kalaupapa was relatively easy. The Hokule'a's inclusion really stemmed from the willingness of the leadership at the Polynesian Voyaging Society to understand the connection between "voyaging" and human health and wellbeing. Of course, Don's love for the ocean and maritime history was a natural assimilation. The interview with Dr. Tamura (a non-Native Hawaiian physician, medical officer) and Nainoa Thompson (Native Hawaiian, navigator and wayfinder) I think was particularly engaging because it spoke to universality of how voyaging offers a broader context for indigenous wellness that goes beyond medical care - but also about indigenous ways of knowing ... like wayfinding ... that remain relevant today.

This ancestral knowledge is precise, reproducible, and generalizable (it works everywhere in the world) and crosses racial/ethnic barriers. Indigenous knowledge is alive and well and rivals some of the greatest scientific discoveries of the modern world.

Seeing the detail and beauty of the Hokule'a model in the lobby of the NLM was a source of incredible cultural pride. It really took your breath away, with its depiction of the waves and sails open to catch the wind! The fact that it was so prominently placed meant to many of us of its prominence of who we were and who we are today! It also spoke volumes for Don's vision to have indigenous people be the center and "heart" of the exhibition. Today, it is displayed in a prominent hotel lobby, and attracts hotel guests and locals alike who are attracted to it for its craftsmanship but also its authenticity ... not to mention the story behind its creation.

At the time of its first launching, it helped heal the Native Hawaiian people by providing an iconic vision of who they were and their rich cultural history as an ocean people. We had lost the sense of WHO we were and Hokule'a helped many to feel that sense of belonging and pride again ... to feel whole again. 
The Southcentral Foundation/Alaska Native Medical Center "Nuka" model of care also is a truly remarkable functional and quality health care delivery model. In addition, the Waianae Coast Comprehensive Health Center is a model of Native Hawaiian healing that works extremely well for the Waianae Coast community that serves a large Native Hawaiian population. Both share many parallel features: traditional healers, communitysupported and focused on indigenous health and wellbeing. However, the products are distinctly different and are difficult to replicate in other settings and context. I think the take-home message is that a health care model for indigenous populations must be "grown organically" and it needs to engage its users ("customer-owners") and it requires dedicated leadership and of course resources, such as funding and policies that will allow them to integrate cultural practices as part of holistic health.

I recall the day we opened the exhibit at NIH, with so many guests, dignitaries, and $\mathrm{NIH}$ leadership present. It was amazing to see an exhibit that was not only visual but also interactive and nearly life-sized and handled with such TLC by the curators and exhibit staff. It really made us proud to be there and to feel that energy and pride. Proud to finally be recognized and to be seen for our indigenous knowledge and cultural practices and how this exhibit would live on... way past all of us.

It was really "moving" to see how NLM and Don Lindberg took the time to share the healing totem pole with as many native communities as possible. Not to mention all the cultural protocol done along the way with healers by its side. It really created the right context and recognition of the spiritual components of the Native Voices exhibition.

I think the amount of work, planning, and execution of the Native Voices exhibition clearly was one of the best examples of the federal government fulfilling its promise to honor and recognize the struggles of both the darker and brighter sides of a painful part of our country's history. It was done with incredible sensitivity, class, and style. I can think of no better person than Don Lindberg to have pulled this off with such resounding success. He really set the standard for any other NIH Institute to follow his incredible example of dedication of time and funds to achieve an extremely high bar for authenticity and told in the first person by Native people themselves.

I completed a traveling exhibit to Charles Drew University in California and a colleague took the exhibit to New Bedford, MA. The response we received at both venues was well attended by community members, students, and in Massachusetts with school children. They were astonished to learn about the "untold" stories of healing and indigenous knowledge - most of all perseverance and it was well received in both places. I received many holiday cards from the group in New Bedford, MA and the group at Charles Drew University were proud to bring the event not just to the library and students/faculty on campus but to open it up to the Native Hawaiian/Pacific Islander community in California. Many many connections were made during those visits.

I still refer people to the online Native Voices exhibition I have not been on it for a while - but it is a reservoir of many of our elders' voices ...some who have now passed on - so it is a treasure trove to see these leaders and healers in their own words. It is a national treasure of the U.S.'s indigenous peoples. Mahalo to Don and the NLM team for bringing this resource to us and to firmly placing the stories shared and the objects in the exhibit to the rest of the U.S. and to honor those of us who remain ... it will serve as a resource for many generations to come. Mahalo mahalo!! 


\section{Katherine Gottlieb M.B.A, D.P.S., Katherine Gottlieb Strategies and former President and CEO, Southcentral Foundation}

When traveling back on a D.C. trip to visit Congressional delegates and Indian Health Service leaders about Alaska Native/American Indian healthcare issues, Ted Mala M.D. scheduled a visit to the National Library of Medicine in Bethesda, MD. It sounded like it would be an interesting visit, especially since we already had a business connection with the National Institutes of Health who shared the same campus.

When our team showed up at the National Library of Medicine, we were greeted by Dr. Lindberg. As we walked through the security entrance, there was an exhibition display to the immediate right of the library. Before the entrance of the Board room there was a wall of previous and current NLM Board of Regents, Newt Gingrich's smile caught my eye. Dr. Lindberg had arranged for all his executive staff to meet with us with a nice lunch prepared. He was pleasant and engaging, we hit it off immediately!

Don (he insisted we address him this way) asked we introduce ourselves and describe the work we were currently doing. He and his group asked many questions. And then we received a great overview of the work the Library was accomplishing. He described the building structure to us; I was amazed to find out it was designed to collapse to secure and save precious books in case of an attack on our country!

Then we toured the building. Offices were on the same level of the board room and then we moved to the first floor where the lives of famous Women in Medicine were on exhibition. The area was in the center of the first floor, and it captured our attention for more than an hour. The information was displayed with video, pictures, and art. We easily could have spent a day or two visiting the exhibition.

Don led us into the library. We moved into a tiny glass walled room. The room was kept at a certain temperature to maintain the life of the books inside. I was given a book to hold and told it was very old and precious. Once I visited Jerusalem and we were in a tunnel deep under the earth where I touched the wall and realized that it was thousands of years old. I felt the same way holding this precious book. When they said it was worth over \$1 million, I quickly handed it back to the care keeper, not wanting to wrinkle or smudge it!

Don led us down through the basement where he showed us his data room, where materials were sent out globally through websites and other means of media distribution. We continued walking through the building and exited. We continued our walk as Dr. Lindberg described campus activities outside of the National Library of Medicine.

Little did I know as we said our good-byes, that the visit would be the start of a multi-year friendship. This is Dr. Lindberg, the amazing relationship builder. We graced the Lindberg's beautiful, warm home, guests of his wonderful wife, Mary. He had me appointed by the President, where I served four years as the first Alaska Native person on the National Library of Medicine's Board of Regents. I spent four years of an amazing educational journey about global health and wellness, met amazing people, approved many of the innovative creative means of connecting NLM to the nation. Don created a means for people to gain knowledge about the achievements of NLM - he invited people to become "Friends" of NLM. During the Friends gatherings, he featured speakers tied to a wonderful dinner event filled with opportunity to network and build new relationships.

One of the best innovative ideas Dr. Lindberg devised was Native Voices. I personally enjoyed how he organized working with the tribes, tribal organizations, and tribal leaders around the project. He wisely asked advice from leaders like Dr. Mala 
before beginning the project. Dr. Lindberg requested, asking permission to engage in a Region from the local people prior to starting his work.

The feedback from the area was that he was respectful and honoring in the way he moved forward. Even his questions during the interview were all well thought out. During my interview, I felt at ease, without tension or worry about the outcome. As I spoke in depth from a personal and professional view, I felt my words would not come back to haunt or harm the Alaska Native people I served, nor myself or family.

The product of the Native Voices, I viewed as a success. It captures historical views that may not be written anywhere else, with real people and personalized story. Dr. Lindberg's rolling out of the final product was also a marvelous experience where he carefully displayed the work as one of his exhibitions in the National Library of Medicine. Southcentral Foundation was highlighted for health innovation and the work achieved through Dr. Mala for traditional healing.

When NLM took Native voices on the road, it was successfully highlighted at the Alaska Native Heritage Center where local people and visitors from throughout the world received this innovative historical education of the Alaska Native, American Indian, and Hawaiian cultures.

The intent of Dr. Lindberg's engagement with the Indigenous people was to expand the outreach activities of the NLM. The National Library of Medicine wanted more outreach. It makes me smile at the thought. NLM's outreach stretched across the U.S. to be very inclusive, not missing or excluding any Indigenous open invitation. It not only served to connect people to NLM but to connect many of the cultures to one another. The achievement of Native Voices not only educated and connected everyone to the National Library of Medicine, but it also served as an educational tool for each culture to learn of one another.

The intent and accomplishment of Native Voices reflected Dr. Lindberg's integrity and creative genius. His natural ability was to connect with people, earning trust with his non-assuming character. This opened the door for tribal leaders to willingly share personal stories and highlight the strengths of diverse cultures. Dr. Lindberg deserves all the recognition and rewards he has achieved during his lifetime and our thanks.

\section{Conclusion}

Dr. Donald Lindberg's Native Voices exhibition is a wonderful legacy, it is a successful educational journey told in traditional story form that will continue to educate people down through the generations about the Alaska Native, American Indian, and Native Hawaiian people. Dr. Lindberg listened to council of traditional leaders. He engaged from the heart, was gentle and inviting. A scholar with high integrity, he won the trust of the people.

It was an honor to know him. This chapter is written with the hope it reveals some of the heart Dr. Lindberg put forward in his work accomplishing the Native Voices exhibition.

\section{References}

[1] Wood FB, Altemus AR, Siegel ER. Native Voices exhibition: stories of health, wellness, and illness from Native Americans, Alaska Natives, and Native Hawaiians. In: Humphreys BL, Logan RA, Miller RA, 
Siegel ER, editors. Transforming biomedical informatics and health information access: Don Lindberg and the U.S. National Library of Medicine. Amsterdam: IOS Press; 2021.

[2] Native Voices interviews and other exhibition resources. [Internet] [cited 2021 July 10]. Available from: https://www.nlm.nih.gov/nativevoices/index.html 